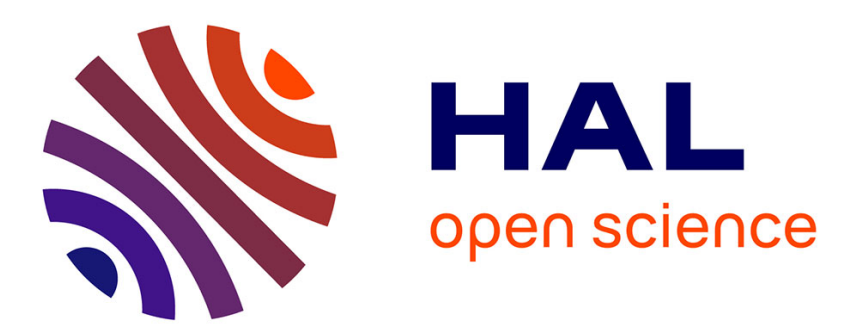

\title{
Dissociating Water at n-Si Photoanodes Partially Covered with Fe Catalysts
}

Kiseok Oh, Vincent Dorcet, Bruno Fabre, Gabriel Loget

\section{To cite this version:}

Kiseok Oh, Vincent Dorcet, Bruno Fabre, Gabriel Loget. Dissociating Water at n-Si Photoanodes Partially Covered with Fe Catalysts. Advanced Energy Materials, 2020, 10 (3), pp.1902963. 10.1002/aenm.201902963 . hal-02438527

HAL Id: hal-02438527

https://hal-univ-rennes1.archives-ouvertes.fr/hal-02438527

Submitted on 5 Nov 2020

HAL is a multi-disciplinary open access archive for the deposit and dissemination of scientific research documents, whether they are published or not. The documents may come from teaching and research institutions in France or abroad, or from public or private research centers.
L'archive ouverte pluridisciplinaire HAL, est destinée au dépôt et à la diffusion de documents scientifiques de niveau recherche, publiés ou non, émanant des établissements d'enseignement et de recherche français ou étrangers, des laboratoires publics ou privés. 


\section{WILEY-VCH}

\section{Dissociating water at $\boldsymbol{n}$-Si photoanodes partially covered with Fe catalysts}

Kiseok Oh, Vincent Dorcet, Bruno Fabre and Gabriel Loget*

K. Oh, Dr. V. Dorcet, Dr. B. Fabre and Dr. G. Loget

Univ Rennes, CNRS, ISCR (Institut des Sciences Chimiques de Rennes)-UMR6226ScanMAT-UMS2001

F-35000 Rennes, France

E-mail: gabriel.loget@univ-rennes1.fr

Keywords: Photoelectrochemistry, Oxygen evolution reaction, Silicon, Iron, Schottky junction

Stable, efficient and low-cost photoanodes are urgently required for manufacturing watersplitting photoelectrochemical cells (PECs). Although silicon is a promising photoelectrode substrate, photocorrosion prevents its use in such devices, especially when employed as photoanodes for oxygen evolution reaction (OER). Here, we show that Fe nanoparticles (NPs), deposited by cathodic electrodeposition onto $n$-Si can promote hole transfer for OER. The influence of the surface coverage, the Si structure as well as the electrolyte is studied here in details. We report that the NP density and the Si structuration drastically affect the photoelectrochemical performance and that the electrolyte influences the stability, allowing to reach operation time as long as $130 \mathrm{~h}$ for these inhomogeneously-coated photoelectrodes.

\section{Introduction}

As energy demands grow tremendously, the production of low-cost and clean renewable energy is of crucial importance for the future. This year, the US Energy Information Administration reported that increases in renewable energy generation will be led by solar and wind energy until 2050 and also expects solar and wind energy to account for nearly $90 \%$ of the total renewable energy growth. ${ }^{[1]}$ Solar energy is infinite, and original methods have been explored to convert, store and distribute it. Among these methods, a remarkable technology referred as "photoelectrochemical cells" (PECs), can be used to electrolyze water upon absorption of solar energy, thus, converting water into energy-rich $\mathrm{H}_{2}$ without carbon emissions. Such devices are 


\section{WILEY-VCH}

based on semiconductor (SC) surfaces immersed in water (i.e. photoelectrodes) which can promote hydrogen evolution reaction (HER) and oxygen evolution reaction (OER) with photogenerated charge carriers. Although many SCs can be employed as PEC photoelectrodes, such as III-V SCs, Si or metal oxides, ${ }^{[2-5]}$ a preference is generally given to short band gap $\left(E_{\mathrm{g}}\right)$ SCs, which can effectively absorb a wide portion of the solar spectrum. Si has a low $E_{\mathrm{g}}$ of 1.1 $\mathrm{eV}$ which makes it active from the IR to UV region but has severe intrinsic drawbacks. First of all, it suffers from its native oxide $\left(\mathrm{SiO}_{\mathrm{x}}\right)$ that forms spontaneously at the $\mathrm{Si} /$ electrolyte interface and can electrically passivate its surface. Second, Si etches chemically in high pH solutions, ${ }^{[6]}$ which are relevant media for water electrolysis. ${ }^{[7]}$ In order to prevent the degeneration of Si photoanodes, numerous studies reported on the use of protection layers consisting of insulating or semiconducting materials. These layers are typically applied onto Si by physical deposition methods such as atomic layer deposition (ALD). ${ }^{[8-12]}$ In addition to this protective layer, a catalytic coating, generally deposited by evaporation or sputtering, is commonly used to enhance the OER kinetics. ${ }^{[2],[11]}$

Recent reports by our group ${ }^{[13],[14]}$ and others, ${ }^{[15-17]}$ have demonstrated that aqueous electrodeposition of transition metals nanoparticles (NPs) on $n$-Si is effective to prepare inhomogeneous $\mathrm{Si} /$ metal Schottky junctions that can be further employed as stable Si-based photoanodes without protection layer. This type of photoanode has been reported, so far, for $n$ $\mathrm{Si} / \mathrm{Ni}^{[13-16]}$ and $n-\mathrm{Si} / \mathrm{Co}^{[17]}$ junctions and it has been recently shown that the performance of these systems can be enhanced by using an additional catalytic shell, typically a hydroxide ${ }^{[13],[18]}$ or a metallic coating, ${ }^{[14],[19]}$ over the NPs. To the best of our knowledge, this phenomenon has never been applied to $n$-Si/Fe junctions so far, which we present for the first time in this article. In addition, we systematically study various parameters such as the Si coverage, the electrolyte composition as well as the $\mathrm{Si}$ structuration and we show that $n$-Si/Fe electrodes can oxidize water efficiently with high Faradaic and photoconversion efficiencies and remarkable stability at moderately alkaline $\mathrm{pH}$. 


\section{WILEY-VCH}

\section{Results and discussion}

\subsection{Preparation and characterization of the photoanodes}

To minimize manufacturing costs, buried-junction-free $n$-Si surfaces were employed as SC absorbers. Two different Si substrates were used and compared: $n$-Si(100) (n-Siplanar) and micropyramidal $n$-Si(111) ( $n$-SimPy). The first one is commercially available and the second one was prepared from $n$-Siplanar by a simple and scalable alkaline treatment (see the experimental section for details). Both surfaces exhibit different optical properties and are composed of planar crystalline facets, ${ }^{[20-22]}$, ensuring a low density of surface defects with respect to other types of structured Si (i.e. black Si or Si nanowires). ${ }^{[14],[23]}$ As shown by the reflectance spectra of Figure 1a, light absorption is enhanced on $n$-SimPy in the 300-1050 nm range, which should be beneficial in terms of photoelectrochemical properties provided that the additionallyabsorbed photons are effectively employed for OER.
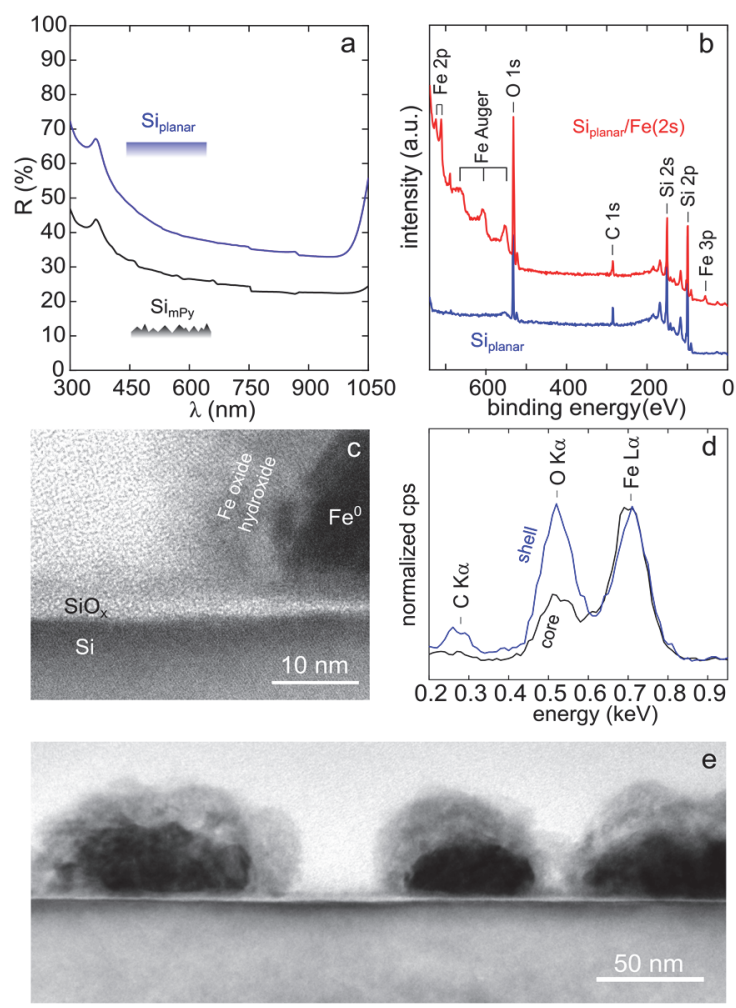

Figure 1. a) Total reflectance spectra of $n$-Siplanar (blue curve) and $n$-SimPy (black curve) surfaces. b) XPS survey spectra of bare $n$-Siplanar (blue curve) and $n$-Siplanar $/ \mathrm{Fe}(2 \mathrm{~s}$ ) (red curve). c) Crosssection high resolution TEM image of $n-\mathrm{Si}$ planar $/ \mathrm{Fe}(2 \mathrm{~s})$ showing the $n-\mathrm{Si} / \mathrm{SiO}_{\mathrm{x}} / \mathrm{Fe}$ interface. d) EDS spectra recorded on the core part (black curve) and the shell part (blue curve) of an individual Fe NP (these spectra were normalized by the intensity of the Fe signal). e) Crosssection TEM image of $n-\mathrm{Si}$ planar $/ \mathrm{Fe}(2 \mathrm{~s})$. 


\section{WILEY-VCH}

The photoanodes were prepared by electrodepositing $\mathrm{Fe}^{0}$ on freshly-hydrogenated $n$-Siplanar or $n$-SimPy. The modification was done at $-1.5 \mathrm{~V}$ vs Saturated Calomel Electrode (SCE) from a slightly acidic solution $(\mathrm{pH}=4.4)$ containing $\left(\mathrm{NH}_{4}\right)_{2} \mathrm{Fe}\left(\mathrm{SO}_{4}\right)_{2}$ (Mohr's salt) which is a Fe source particularly stable to oxidation (a typical chronoamperometry (CA) curve is shown in Figure S1). X-ray photoelectron spectra (XPS, Figure 1b) recorded before and after electrodeposition, confirmed the presence of the expected elements, namely, Si, Fe and O. The oxygen originates from $\mathrm{SiO}_{\mathrm{x}}$ and the outermost part of the Fe electrodeposits which are covered by a native oxide/hydroxide shell, ${ }^{[24]}$ in good agreement with what is observed in the $\mathrm{Fe} 2 \mathrm{p}$ region of the XPS spectrum (Figure S2). Transmission electron microscopy (TEM) allowed visualizing the junction (Figure 1c and e). These images, together with the localized energy-dispersive spectra (EDS, Figure1d) confirmed these XPS results by clearly revealing that the Si was covered by a $\sim 2 \mathrm{~nm}$-thick $\mathrm{SiO}_{\mathrm{x}}$ layer and that $\mathrm{Fe}$, deposited in the form of $\mathrm{NPs}$, consisted of a $\mathrm{Fe}^{0}$ metal core shielded by an oxide/hydroxide shell having a thickness in the range of 10 to $20 \mathrm{~nm}$. The presence of a higher $\mathrm{O}$ to $\mathrm{Fe}$ ratio in the shell with respect to the NP core is clear from the localized EDS spectra.

The influence of the electrodeposition time ( $\left.t_{\text {edep }}\right)$ was analyzed by scanning electron microscopy (SEM). As shown in Figure 2a,b, $t_{\text {edep }}$ was found to influence both the Fe NPs size and the Si coverage for the two types of substrates. The geometrical coverage surface (determined on $n$-Siplanar) varied from $5 \%$ for $t_{\text {edep }}=0.5 \mathrm{~s}$ to $43 \%$ for $t_{\text {edep }}=5 \mathrm{~s}$ (Figure S3). 


\section{WILEY-VCH}
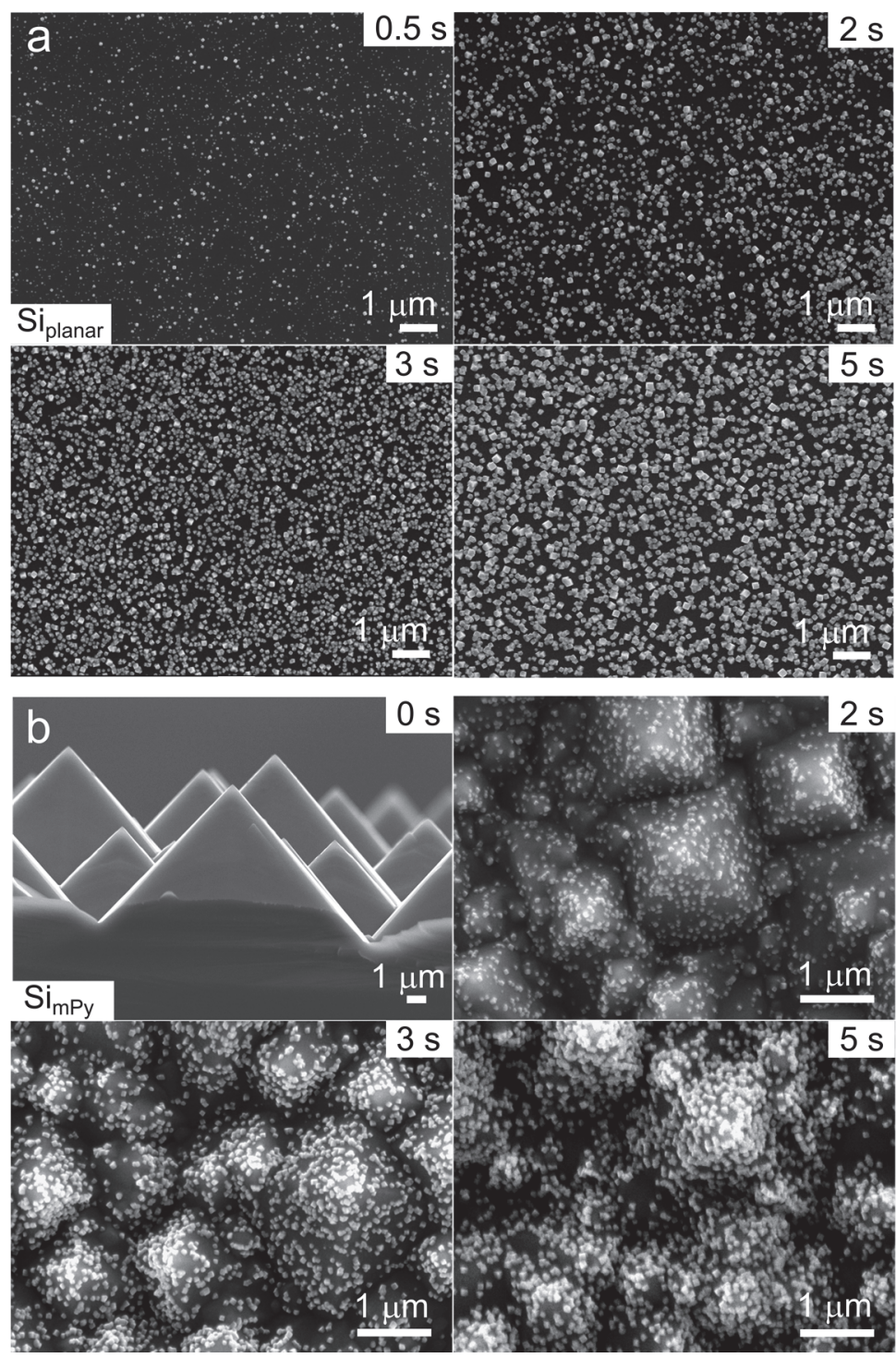

Figure 2. a) Top view SEM images showing Fe NPs electrodeposited on $n$-Siplanar, with times varying from 0.5 to $5 \mathrm{~s}$. b) Cross-section (top left) and top-view SEM images showing Fe NPs electrodeposited on $n$-SimPy, with times varying from 0 to $5 \mathrm{~s}$.

\subsection{OER at $\mathrm{pH} 13.6$ and the effect of the surface coverage}

$n$-Si $i_{\text {planar }} / \mathrm{Fe}$ electrodes prepared with $t_{\text {edep }}$ varying from 0 to $5 \mathrm{~s}$ (denoted here as $n$ $\left.\mathrm{Si}_{\text {planar }} / \mathrm{Fe}\left(t_{\text {edep }}\right)\right)$ were first investigated for OER in $1 \mathrm{M} \mathrm{NaOH}$. As shown in Figure $\mathrm{S} 4$, all electrodes were inactive in the anodic regime in the dark (dark current density $<0.1 \mathrm{~mA} \mathrm{~cm}{ }^{-2}$ ) but exhibited large photocurrents under AM 1.5G simulated sunlight $\left(100 \mathrm{~mW} \mathrm{~cm} \mathrm{~cm}^{-2}\right)$, demonstrating their OER activity. The photoelectrochemical performance of the electrodes was evaluated by cyclic voltammetry (CV, Figure 3a) and their stability was tested by CA at $2 \mathrm{~V}$ vs reversible hydrogen electrode (RHE) (Figure 3b). The CV analysis showed the inactivity of 


\section{WILEY-VCH}

the uncoated $n$-Siplanar $/ \mathrm{Fe}(0 \mathrm{~s})$ electrode for OER (black $\mathrm{CV}$ ), which underwent electrical passivation by the formation of a dense $\mathrm{SiO}_{\mathrm{x}}$ layer during anodic polarization. Besides, it revealed a peculiar behavior for the two extreme electrodeposition times: 0.5 and $5 \mathrm{~s}$ (yellow and purple $\mathrm{CVs})$. Indeed, $n$-Siplanar $/ \mathrm{Fe}(0.5 \mathrm{~s})$ deactivated rapidly, as shown by the photocurrent decay during the voltammetry and $n-\mathrm{Si}_{\text {planar }} / \mathrm{Fe}(5 \mathrm{~s})$ exhibited the most anodic onset potential ( $E_{\text {onset, }}$ arbitrary set for $j=200 \mu \mathrm{A} \mathrm{cm} \mathrm{cm}^{-2}$ ) of $1.36 \mathrm{~V}$. The other photoelectrodes exhibited $E_{\text {onset }}$ relatively close to the standard potential $\left(E^{0}\right)$ of the $\mathrm{O}_{2} / \mathrm{H}_{2} \mathrm{O}$ redox couple, that is, $\left(E^{0} \mathrm{O}_{2} / \mathrm{H}_{2} \mathrm{O}=\right.$ $1.23 \mathrm{~V}$ vs RHE); $1.18 \pm 0.01 \mathrm{~V}$ vs RHE for $n$-Siplanar $/ \mathrm{Fe}(1 \mathrm{~s}), \mathrm{Fe}(1.5 \mathrm{~s})$ and $\mathrm{Fe}(2 \mathrm{~s}))$ and $1.26 \mathrm{~V}$ vs RHE for $n-\mathrm{Si}_{\text {planar }} / \mathrm{Fe}(3 \mathrm{~s})$ (Figure $\left.\mathrm{S} 5\right)$. The photovoltage $\left(V_{\mathrm{oc}}\right)$ was estimated to $0.43 \mathrm{~V}$ by comparing the $E_{\text {onset }}$ obtained on photoactive $n-\mathrm{Si}_{\text {planar }} / \mathrm{Fe}(2 \mathrm{~s})$ (green $\mathrm{CV}$ ) with the one recorded on non-photoactive $p^{+}-\mathrm{Si}_{\text {planar }} / \mathrm{Fe}$ recorded in the dark (grey CV).

In contrast, the photocurrent densities $(j)$ were strongly dependent on $t_{\text {edep }}$, which can be easily understood by considering the dependence of light absorption by the $n$-Si substrate with the surface coverage. Moreover, stability (Figure $3 \mathrm{~b}$ ) was also dependent on $t_{\text {edep. }}$ It is also interesting to note that, in certain cases, CA measurements revealed an increase in $j$ during OER, noticeable for $n-\mathrm{Si}_{\text {planar }} / \mathrm{Fe}(2 \mathrm{~s})$ (green CA) and $n-\mathrm{Si}_{\text {planar }} / \mathrm{Fe}(5 \mathrm{~s})$ (purple CA) and more abrupt for $n$-Siplanar/Fe(3s) (orange CA). This phenomenon is likely caused by a chemical or physical evolution of the Fe coating during OER, affecting the light transmission through the Fe coating. Figure $3 \mathrm{c}$ gathers the maximum photocurrent density $\left(j_{\max }\right.$, measured at $2 \mathrm{~V}$ vs RHE on the CVs) and the stability time ( $t_{\text {stab }}$, defined as the time required to reach $80 \%$ of $j_{\max }$ ) as a function of $t_{\text {edep. }}$ These plots show that, except for $\mathrm{Si}_{\text {planar }} / \mathrm{Fe}(0.5 \mathrm{~s})$ whose instability is such that $j_{\max }$ cannot be reached during the CV cycle (yellow CV in Figure $3 a$ ), $j_{\text {max }}$ decreases with increasing $t_{\text {edep }}$ because of the reduced light absorption by Si. However, stability is improved with higher surface coverage (Figure 3c). These trends are in very good agreement with that previously reported on $\mathrm{Si}$ planar/Ni systems. ${ }^{[25]}$ 


\section{WILEY-VCH}
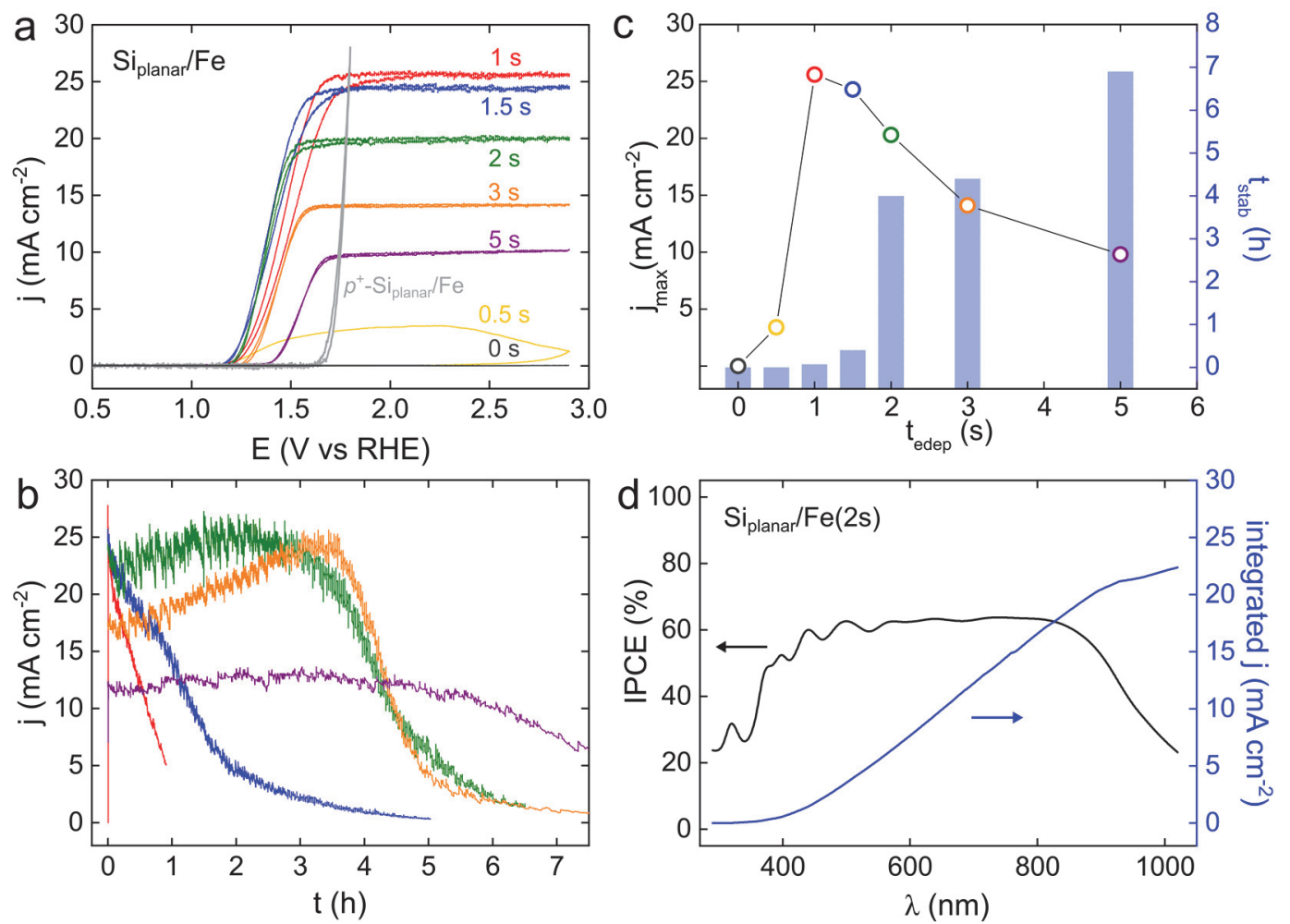

Figure 3. a) $\mathrm{CVs}$ (scan rate $=100 \mathrm{mV} \mathrm{s}^{-1}$ ) and b) $\mathrm{CA}$ curves recorded at $2 \mathrm{~V}$ under illumination in $1 \mathrm{M} \mathrm{NaOH}$ on $n$-Siplanar $/ \mathrm{Fe}(0 \mathrm{~s})$ (black), $n$-Siplanar $/ \mathrm{Fe}(0.5 \mathrm{~s})$ (yellow), $n$-Siplanar $/ \mathrm{Fe}(1 \mathrm{~s})$ (red), $n$ $\mathrm{Si}_{\text {planar }} / \mathrm{Fe}\left(1.5 \mathrm{~s}\right.$ ) (blue), $n$-Siplanar $/ \mathrm{Fe}(2 \mathrm{~s})$ (green), $n$-Si $\mathrm{i}_{\text {planar }} / \mathrm{Fe}(3 \mathrm{~s})$ (orange), and $n$-Siplanar $/ \mathrm{Fe}(5 \mathrm{~s}$ ) (purple). The $\mathrm{CV}$ recorded in the dark on $p^{+}-\mathrm{Si}_{\text {planar }} / \mathrm{Fe}(2 \mathrm{~s})$ is shown in grey. c) Plot of the maximum photocurrent ( $j_{\max }$, colored disks) and the stability time ( $t_{\mathrm{stab}}$, blue bars) as a function of the electrodeposition time ( $\left.t_{\text {edep }}\right)$. d) IPCE spectrum recorded on $n-S_{i}$ planar $/ \mathrm{Fe}(2 \mathrm{~s})$ at $2 \mathrm{~V}$ in 1 $\mathrm{M} \mathrm{NaOH}$ (black curve) and corresponding integrated photocurrent (blue curve).

These results suggest the electrodeposition time of $2 \mathrm{~s}$ as a good tradeoff between activity and stability, which will be used in the following. The incident photon-to-current efficiency (IPCE) spectrum of $n$-Siplanar/Fe(2s), recorded at $2 \mathrm{~V}$ vs RHE (Figure 3d) is in good agreement with the CA data and presents a maximum conversion efficiency of $\sim 60 \%$ between 500 and $850 \mathrm{~nm}$.

\subsection{OER at pH 9.6 and influence of the Si structure}

The electrolyte was then replaced by a moderately alkaline K-borate/Li-borate buffer $(\mathrm{pH}=$ 9.6). The $\mathrm{CV}$ recorded for $n-\mathrm{Si}$ lanar $/ \mathrm{Fe}(2 \mathrm{~s})$ at $\mathrm{pH} 9.6$ is shown in black in Figure $4 \mathrm{a}$ and revealed slightly lower performances when compared to the $\mathrm{CV}$ obtained at $\mathrm{pH} 13.6$ (green $\mathrm{CV}$, Figure 3a), as shown by a higher onset potential of $1.39 \mathrm{~V}$. As it was the case in $1 \mathrm{M} \mathrm{NaOH}$, the uncoated surface $n-\mathrm{Si} / \mathrm{Fe}(0 \mathrm{~s})$ exhibited no photocurrent, demonstrating the need to have Fe NPs on the surface to promote OER in this medium. The comparison between the CV obtained on 


\section{WILEY-VCH}

the photoactive $n$-Siplanar $/ \mathrm{Fe}(2 \mathrm{~s})$ and the non-photoactive $p^{+}-\mathrm{Si}_{\text {planar }} / \mathrm{Fe}$ (grey CV) allows estimating a $V_{\text {oc }}$ value of $0.39 \mathrm{~V}$, relatively close to the one previously determined in $1 \mathrm{M} \mathrm{NaOH}$. However, long term electrolysis (Figure 4b) shows that this medium affords unprecedented operation durations $>130 \mathrm{~h}$. Such a remarkable electrolyte effect has been previously reported in the case of vapor-phase deposited $\mathrm{Ni}$ thin film and was attributed to an inhibition of the volume expansion of the $\mathrm{Ni}(\mathrm{OH})_{2}$ catalytic phase by the $\mathrm{Li}^{+}$ions. ${ }^{[26]}$ If a similar phenomenon probably also occurs on the $\mathrm{Fe}(\mathrm{OH})_{2}$ at the outer part of the NPs, it can also be hypothesized that the lower $\mathrm{pH}$ helps to promote photoanode integrity by decreasing the chemical etching of $\mathrm{Si}, \mathrm{SiO}_{\mathrm{x}},{ }^{[6]}$ and the catalyst. The quantity of produced $\mathrm{O}_{2}$ was determined by an optical detection system during a 30 min-long preparative electrolysis (Figure $4 \mathrm{~d}$ ) at $2.3 \mathrm{~V}$ in the $\mathrm{K}-$ borate/Liborate buffer. This analysis confirmed that the reaction product was $\mathrm{O}_{2}$ with a production rate of $189.7 \mu \mathrm{mol} \mathrm{h}^{-1} \mathrm{~cm}^{-2}$. The theoretical number of mole of $\mathrm{O}_{2}$ was calculated based on the electrical charge that was consumed during the electrolysis (Figure S6) and is plotted as red circles in Figure 4d. Comparison of the theoretical and experimental data shows that a quantitative Faradaic efficiency $\eta$ was obtained.

The effect of the Si structure was also investigated and $n-\mathrm{Si}_{\mathrm{mPy}} / \mathrm{Fe}$ surfaces prepared with different $t_{\text {edep }}$ were also tested for OER. CV studies (Figure S7) showed that $t_{\text {edep }}$ had the same influence on $j_{\max }$ as for $n$-Siplanar/Fe surfaces. Overall, $n$-SimPy provided higher performance $\left(E_{\text {onset }}=1.24 \mathrm{~V}\right.$ and $j_{\max }=34 \mathrm{~mA} \mathrm{~cm}^{-2}$ ), as it can be observed by comparing the CVs and the IPCE spectra recorded on $n-\operatorname{SimPy} / \mathrm{Fe}(2 \mathrm{~s})$ and $n$-Siplanar $/ \mathrm{Fe}(2 \mathrm{~s})$. This improvement is also observed in $1 \mathrm{M} \mathrm{NaOH}$ (Figure S7 and Figure 2a) and is explained by the enhanced absorption of photons by the micropyramidal array, which are converted to holes and employed effectively for the OER reaction. 


\section{WILEY-VCH}
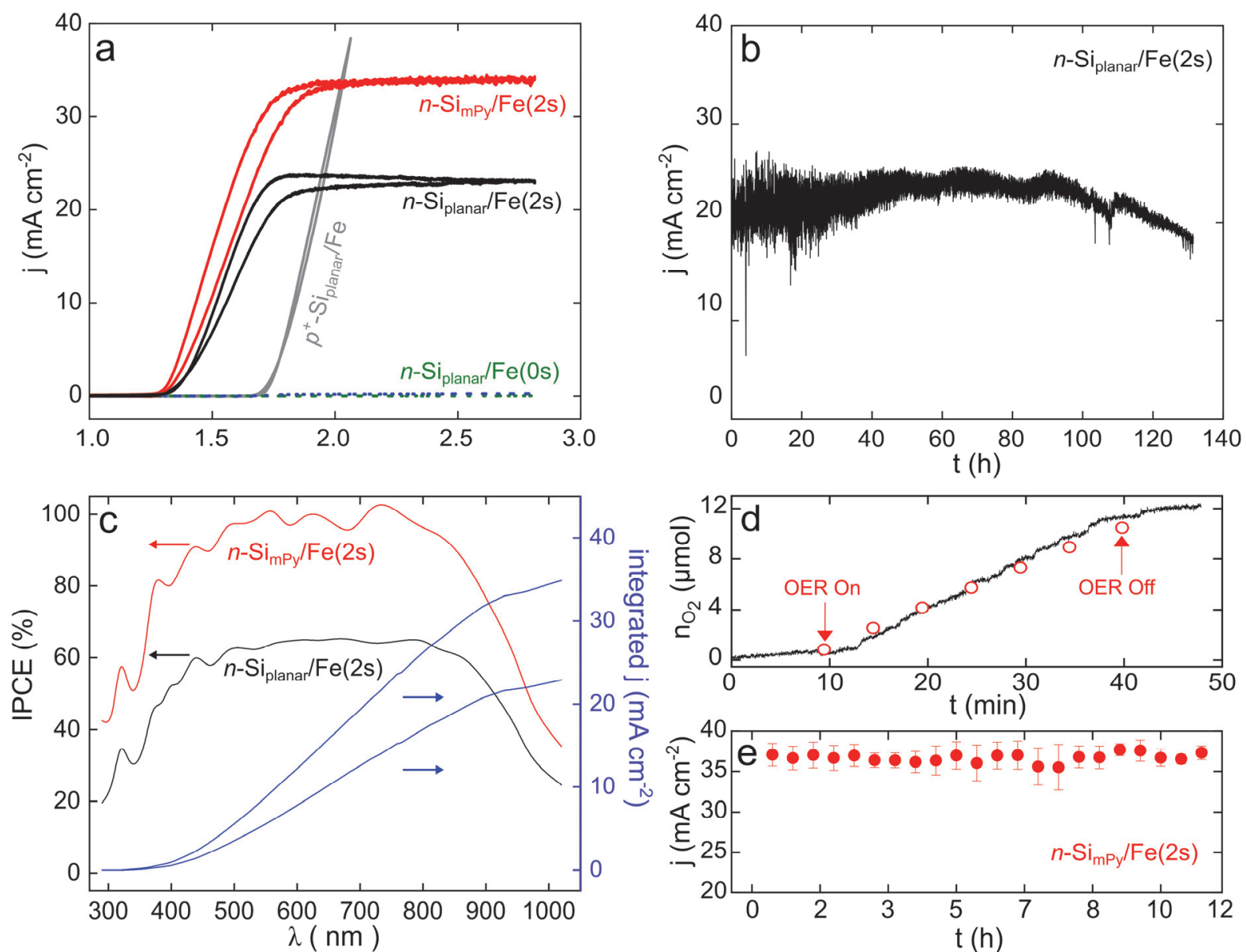

Figure 4. a) $\mathrm{CVs}$ (scan rate $\left.=100 \mathrm{mV} \mathrm{s}^{-1}\right)$ recorded under illumination in borate buffer $(\mathrm{pH}=$ 9.6) on $n-\mathrm{Si}_{\text {planar }} / \mathrm{Fe}(2 \mathrm{~s})$ (black), $n-\mathrm{Si}_{\mathrm{mPy}} / \mathrm{Fe}(2 \mathrm{~s})$ (red), and $n-\mathrm{Si}$ planar $/ \mathrm{Fe}(0 \mathrm{~s})$ (green dotted line). The CV recorded in the dark for $p^{+}-\mathrm{Si}_{\text {planar }} / \mathrm{Fe}$ (grey) and $n-\mathrm{Si}_{\mathrm{mPy}} / \mathrm{Fe}(2 \mathrm{~s})$ (blue dotted line) are also shown. b) CA recorded under illumination in borate buffer at $2.3 \mathrm{~V}$ on $\mathrm{Si}_{\text {planar }} / \mathrm{Fe}(2 \mathrm{~s})$. c) IPCE spectra recorded at $2.3 \mathrm{~V}$ in borate buffer on $\mathrm{Si}_{\text {planar }} / \mathrm{Fe}(2 \mathrm{~s})$ (black curve) and $\mathrm{Si}_{\mathrm{mPy}} / \mathrm{Fe}(2 \mathrm{~s})$ (red curve) and corresponding integrated photocurrent (blue curves, bottom: $\mathrm{Si}_{\text {planar }} / \mathrm{Fe}(2 \mathrm{~s})$, top: $\mathrm{Si}_{\mathrm{mPy}} / \mathrm{Fe}(2 \mathrm{~s})$ ). d) Experimentally-measured (black curve) and theoretical (red disks) $\mathrm{O}_{2}$ detection curves, obtained on $\mathrm{Si}_{\text {planar }} / \mathrm{Fe}(2 \mathrm{~s})$ in borate buffer during an electrolysis at $2.3 \mathrm{~V}$ under illumination with simulated sunlight. e) $j$ - $t$ curves obtained by averaging the data recorded with three $\mathrm{SimPy}_{\mathrm{m}} \mathrm{Fe}(2 \mathrm{~s})$ surfaces at $2.3 \mathrm{~V}$ in borate buffer.

Eleven hours-long electrolyzes at $2.3 \mathrm{~V}$ vs RHE were performed on three independently prepared $n-\mathrm{SimPy} / \mathrm{Fe}(2 \mathrm{~s})$ electrodes (Figure $4 \mathrm{e})$. The averaged $j\left(36 \mathrm{~mA} \mathrm{~cm}^{-2}\right)$ obtained from CA was in good agreement with the $j_{\max }$ value of the CVs $\left(34 \mathrm{~mA} \mathrm{~cm}^{-2}\right)$ and the integrated photocurrent derived from the IPCE curve $\left(35 \mathrm{~mA} \mathrm{~cm}^{-2}\right)$ (Figure $4 \mathrm{c}$, top blue curve), showing the good reproducibility of our method. 


\section{WILEY-VCH}

\subsection{Post-electrolysis analyses}

Finally, the chemical composition and the morphology of the electrodes was investigated after electrolysis. SEM images acquired on $n$-Siplanar $/ \mathrm{Fe}(2 \mathrm{~s})$ surfaces that were used for $3 \mathrm{~h}$ in $1 \mathrm{M}$ $\mathrm{NaOH}$ and $130 \mathrm{~h}$ in K-borate/Li-borate buffer (Figure S8) demonstrate that, in both cases, the Si surface morphology was preserved from alkaline etching. This implies that a robust interface between the $\mathrm{Si}$ absorber and the NPs is generated during Fe electrodeposition. SEM also indicates that more Fe NPs maintained on the Si substrate in the K-borate/Li-borate buffer and that the surface of Fe NPs etched during operation in $\mathrm{NaOH}$, which could be the reason for the electrochemical deactivation (Figure $3 b$ ). The oxidation state of the outermost part of the Fe NPs was analyzed by comparing the Fe $2 p$ region on the XPS spectra recorded before and after electrolysis in both media (Figure S2). Both revealed both disappearance of the $\mathrm{Fe}^{0} 2 \mathrm{p}_{3 / 2}$ characteristic peak at $706.5 \mathrm{eV}^{[24]}$ and the persistency of the oxidized Fe at $710.8 \mathrm{eV}$ after electrolysis. $^{[27]}$

\section{Conclusion}

To conclude, we reported that Fe NPs, generated through cathodic electrodeposition onto $n$-Si can promote hole transfer from the Si absorber to the electrolyte for achieving OER under solar illumination at alkaline $\mathrm{pH}$. We have shown that NP coverage is crucial for performance, as it strongly affects photocurrent density and stability. We have also shown the importance of the electrolyte $\mathrm{pH}$ for that system, which can drastically improve the operation time. In particular, we reported that replacing the $1 \mathrm{M} \mathrm{NaOH}$ solution $(\mathrm{pH}$ 13.6) by a mixed K-borate/Li-borate buffer ( $\mathrm{pH}$ 9.6) allowed to impressively improve the operation time from $4 \mathrm{~h}$ to more than 130 $\mathrm{h}$, which is among the longest time reported for this type of $n$-Si-based photoanode (Table $\mathrm{S} 1$ ). Finally, we have highlighted the importance of the Si structuration by demonstrating a $\sim 40 \%$ enhancement of the maximum photocurrent density when employing micropyramidal $n$-Si, allowing to reach state-of-the-art photocurrent densities when compared with similar systems (the performance comparison for several reported electrodes are shown in Table S1). In addition 


\section{WILEY-VCH}

to providing a new (buried-junction and protection-layer-free) photoanode entirely based on abundant materials and low-cost methods, these results generalize the recent research reported on $n-\mathrm{Si} / \mathrm{Co}^{[17]}$ and $n-\mathrm{Si} / \mathrm{Ni}^{[13]}$ inhomogeneous junctions by showing that other catalyticallyactive transition metals can be electrodeposited on $n$-Si. Next efforts will be given on the detailed elucidation of the structures and species involved at the $n-\mathrm{Si} / \mathrm{Fe}$ and the Fe/electrolyte interfaces, as these are crucial for stability and catalytic activity, respectively.

\section{Experimental Section}

Materials and reagents: Acetone (MOS electronic grade, Erbatron from Carlo Erba) and anhydrous ethanol (RSE electronic grade, Erbatron from Carlo Erba) were used without further purification for cleaning the Si surfaces. The ultrapure water had a resistivity of $18.2 \mathrm{M} \Omega \mathrm{cm}$ (Purelab Classic UV from Veolia Water STI). HF (50\% aq. solutions) and $\mathrm{NaOH}$ ( $>98 \%$, ACS reagent) were purchased from Sigma-Aldrich and $\mathrm{LiOH}(98 \%)$ was purchased from Alfa Aesar. Ammonium iron(II) sulfate heptahydrate (98-101\%) was purchased from Panreac Quimica Sau, ammonium sulfate from Merck and boric acid (99\%) from Acros. $\mathrm{KOH}(\geq 85 \%$, Merck) and 2-

propanol (HPLC grade, VWR) were used for preparing the pyramidal structure by chemical etching of $n$-Si. The chemicals used for the cleaning and etching of the Teflon vials were sulfuric acid (96\%, VLSI grade Selectipur, BASF) and hydrogen peroxide (30\%, VLSI, SigmaAldrich). The $n$-type Si wafers $(0.3-0.7 \Omega \cdot \mathrm{cm}$ resistivity, phosphorus-doped, double side polished, $280 \mu \mathrm{m}$ thickness, (100)) and the $p^{+}$-type wafers $(0.001-0.005 \Omega \mathrm{cm}$ resistivity, borondoped, single side polished, $500 \mu \mathrm{m}$ thickness, (100)) were purchased from Siltronix and University Wafers, respectively. The Fe electrodeposition electrolyte was a freshly-prepared aqueous solution containing ammonium iron(II) sulfate $(0.1 \mathrm{M})$ and ammonium sulfate $(0.6 \mathrm{M})$. Electrolysis solutions were $1 \mathrm{M} \mathrm{NaOH}$ (measured $\mathrm{pH}=13.6$ ) and $\mathrm{K}$-borate/Li-borate (measured 
$\mathrm{pH}=9.6$ ). The latter was composed of $1.139 \mathrm{~g}$ of $\mathrm{LiOH} \cdot \mathrm{H}_{2} \mathrm{O}, 1.9 \mathrm{~g}$ of $\mathrm{KOH}$ and $6 \mathrm{~g}$ of boric acid in $50 \mathrm{~mL}$ of ultrapure water.

Surface preparation: All Teflon vials and tweezers used for cleaning of Si were previously decontaminated in $3 / 1 \mathrm{v} / \mathrm{v}$ concentrated $\mathrm{H}_{2} \mathrm{SO}_{4} / 30 \% \mathrm{H}_{2} \mathrm{O}_{2}$ at $105{ }^{\circ} \mathrm{C}$ for $30 \mathrm{~min}$, followed by copious rinsing with ultrapure water. The $n$-type $\mathrm{Si}$ (100) wafers were cut in $1.6 \times 4.8 \mathrm{~cm}^{2}$ rectangles and degreased by ultrasonication $(10 \mathrm{~min})$ in acetone, ethanol and ultrapure water in Teflon vials. The surfaces were then cleaned in $3 / 1 \mathrm{v} / \mathrm{v}$ concentrated $\mathrm{H}_{2} \mathrm{SO}_{4} / 30 \% \mathrm{H}_{2} \mathrm{O}_{2}$ at $105{ }^{\circ} \mathrm{C}$ for $30 \mathrm{~min}$, followed by copious rinsing with ultrapure water. They were dried under an Ar stream.

Silicon pyramids preparation: A Si piece was cut by $2 \times 3 \mathrm{~cm}^{2}$ rectangles. The Si piece was immersed at $105^{\circ} \mathrm{C}$ in an etching solution consisting of $2.5 \mathrm{wt} \% \mathrm{KOH}$ and $5 \mathrm{vol} \%$ of 2 -propanol which was stirred with a magnetic stirrer at $1000 \mathrm{rpm}$ for $50 \mathrm{~min}$. After the etching, Si was rinsed with a copious amount of ultrapure water and dried under an Ar flow.

Electrodeposition: Before electrodeposition, the native Si oxide of $1 \times 1.5 \mathrm{~cm}^{2}$ wafer piece was removed by dipping for $2 \mathrm{~min}$ in $5 / 1 \mathrm{v} / \mathrm{v}$ ultrapure water $/ 50 \%$ aq. $\mathrm{HF}$, then it was dried under an Ar flow. An Ohmic contact was established on the top of the Si surface by scratching it and applying a droplet of InGa eutectic and a layer of silver paste. The backside of the surface was covered with hydrophobic tape (3M $5490 \mathrm{HD}$ ). The surface was partially immersed into the Fe electrolyte and the electrical contact with the potentiostat (SP 150, Biologic) was done outside the electrolyte with a crocodile clip. A KCl-Saturated Calomel Electrode (SCE) was used as a reference electrode and a Pt plate was used as a counter electrode. The electrodeposition was done by applying $-1.5 \mathrm{~V}$ for times ranging from 0.5 to $5 \mathrm{~s}$. The electrodeposition on $p^{+}$-Si was done at the same potential and was stopped when the charge equaled the one consumed for $n$ $\mathrm{Si} / \mathrm{SiO}_{\mathrm{x}} / \mathrm{Fe}(2 \mathrm{~s})$. 


\section{WILEY-VCH}

Electrode fabrication: The Si surfaces were then processed to fabricate electrodes. First, the backside of the surface was scratched with a diamond glass cutter again to make fresh trenches. An ohmic contact was established on the backside of the Si surface with a metal wire by first scrubbing the surface with a diamond glass cutter and then applying a droplet of InGa eutectic. A layer of silver paste was then deposited on the contact. After drying of the silver paste, the metal wire was inserted in a glass capillary, and the electrode area was defined on the front side with an epoxy-based resin (Loctite 9460, Henkel) that also covered all the backside of the surface and a part of the glass capillary in order to ensure a proper shielding of the Ohmic contact. The electrode was then placed into an oven at $90{ }^{\circ} \mathrm{C}$ overnight to cure the resin. $\mathrm{SimPy}$ electrodes were prepared by a two-step process. The backside of the electrode was cured with the resin in the oven for $1 \mathrm{~h}$, then the micropyramidal frontside was partially covered with the resin but cured in the air overnight to avoid the penetration of the resin within the pyramids. The active surface area of all electrodes was determined using the ImageJ software.

Photoelectrochemical measurements: The cyclic voltammetry (CV) was performed in a homemade two-neck photoelectrochemical (PEC) cell comprising a quartz window, a porous glass bridge separating the anodic and cathodic compartments and a Pt cylinder used as a counter electrode. $\mathrm{A} \mathrm{Hg} / \mathrm{HgO}$ electrode was used as the reference electrode in the $1 \mathrm{M} \mathrm{NaOH}$ solution and SCE was used as the reference electrode in the K-borate/Li-borate solution. The cell was filled with the electrolyte and the $\mathrm{Si} / \mathrm{Fe}$ electrode was disposed in front of the quartz window and used as a working electrode. The light was provided by a solar simulator (LS0106, LOT Quantum Design) equipped with an AM 1.5G filter. The power intensity of the light source, where the photoanode was located, was set to $100 \mathrm{~mW} \mathrm{~cm}{ }^{-2}$ using an ILT1400 radiometer (International Light Technologies). The potentials versus $\mathrm{Hg} / \mathrm{HgO}$ and $\mathrm{SCE}$ were converted into potentials versus reversible hydrogen electrode (RHE) using the following equations: 


\section{WILEY-VCH}

$$
\begin{gathered}
E_{R H E}=E_{H g / H g O}+0.098+0.059 p H=E_{H g / H g O}+0.900(\text { measured } \mathrm{pH}=13.6) \\
E_{R H E}=E_{S C E}+0.244+0.059 p H=E_{S C E}+0.810(\text { measured } \mathrm{pH}=9.6)
\end{gathered}
$$

All reported potentials were intentionally not corrected by the Ohmic drop. Unless specified, the CVs reported in this work were recorded at $100 \mathrm{mV} \mathrm{s}^{-1}$ and, unless specified, all potential values reported in the manuscript are versus RHE. Electrochemical measurements were performed with a Zennium potentiostat (Zahner). IPCE measurements were performed with a CIMPS-QE IPCE 3 workstation (Zahner) comprising a TLS03 tunable light source controlled by a PP211 potentiostat in the same cell as the one used for classical electrochemical experiments. The applied potentials were $2 \mathrm{~V}$ vs $\mathrm{RHE}$ in $\mathrm{NaOH}$ solution and $2.3 \mathrm{~V}$ vs RHE in K-borate/Li-borate solution. The light modulation frequency was $1 \mathrm{~Hz}$, the settling time was 10 $\mathrm{s}$ and the number of counts 25 . The Thales software provided the spectra in photocurrent efficiency (A/W) or IPCE (\%). In order to check the validity of the IPCE measurements, the IPCE spectra were first converted into photocurrent density (in A/W). We then used the AM 1.5G reference solar spectrum obtained from the ASTM (American Society for Testing Materials) webpage (http://rredc.nrel.gov/solar/spectra/am1.5/) in order extract the incident power distribution as a function of the wavelength in the spectral range of our measurements.

Faradaic efficiency measurement: For measuring the amount of produced $\mathrm{O}_{2}$ and the Faradaic efficiency, the cell was sealed with a silicone resin (CAF 4, Elkem). Two needles perforating a septum were used as gas inlet and outlet for degassing the anolyte compartment that contained the working electrode: $\mathrm{Si}_{\mathrm{planar}} / \mathrm{Fe}(2 \mathrm{~s})$ and the reference electrode: SCE. The catholyte compartment that contained a Pt-cylinder counter electrode was appropriately sealed. The Kborate/Li-borate solution was degassed with Ar for $1 \mathrm{~h}$. The electrolysis was carried out potentiostatically by applying $1.5 \mathrm{~V}$ vs $\mathrm{SCE}$ for $30 \mathrm{~min}$. During electrolysis, evolved $\mathrm{O}_{2}$ accumulated in the anolyte headspace and was measured in-situ by the Neofox-kit-probe oxygen measurement system allowing to measure the $\mathrm{O}_{2}$ percentage in the gas phase which was 


\section{WILEY-VCH}

converted in the number of moles $\left(n_{\mathrm{O}_{2}}\right.$,prod). To determine Faradaic efficiency, the consumed charge $Q$ was employed to calculate the theoretical number of moles of $\mathrm{O}_{2}\left(n_{\mathrm{O}_{2}}\right.$,theo $)$ as follows:

$$
n_{O_{2}, \text { theo }}=\frac{Q}{4 F}
$$

with $F$ being the Faraday constant. The Faradaic efficiency, $\eta$ was then determined using the following relation:

$$
\eta=\frac{n_{O_{2}, \text { prod }}}{n_{O_{2}, \text { theo }}} \times 100(\%)
$$

Surface characterization: Scanning electron microscopy (SEM) was performed using a JSM 7100F (JEOL). SEM picture analysis was performed using the ImageJ software. XPS measurements were performed with an $\mathrm{Mg} \mathrm{K}$ alpha $(\mathrm{h} v=1254.6 \mathrm{eV}) \mathrm{X}$-ray source using a VSW HA100 photoelectron spectrometer with a hemispherical photoelectron analyzer, working at an energy pass of $20 \mathrm{eV}$ for survey and resolved spectra. The surface total reflectance spectra were acquired on a Shimadzu UV-3600Plus spectrophotometer with an integrating sphere (ISR-603). A sample of extra pure $\mathrm{BaSO}_{4}$ was used as the $100 \%$ reflectance reference (Nacalai Tesque). A Teflon mask was used to perform the measurements and ensure good reproducibility. The total reflectance was measured with an incident beam with an angle of $8^{\circ}$ to include the specular component. Transmission electron microscopy (TEM) was performed using a JEOL JEM-2100 LaB6 operating at $200 \mathrm{kV}$ and equipped with an Oxford Silicon Drift Detectors (SSD) X-Max ${ }^{\mathrm{N}}$ 80T for Energy-dispersive X-ray Scattering (EDS) measurement. The Cross-section sample was first thinned using a tripod to approximately $20 \mu \mathrm{m}$ and a final polishing was performed by ion milling with a Fischione ion mill model 1010.

\section{Supporting Information}

Supporting Information is available from the Wiley Online Library or from the author. 


\section{WILEY-VCH}

\section{Acknowledgments}

This work is funded by ANR (project EASi-NANO, ANR-16-CE09-0001-01). We acknowledge Loïc Joanny and Francis Gouttefangeas from ScanMAT/CMEBA for SEM analyses. Stéphanie Fryars and Ludivine Rault from ISCR/THEMIS are warmly acknowledged for the preparation of the samples that were used for TEM. Sophie Ollivier is acknowledged for helpful discussion. We thank Cristelle Mériadec and Soraya Ababou-Girard (IPR) for the XPS measurements. Antoine Vacher is acknowledged for the optical measurements.

Received: ((will be filled in by the editorial staff))

Revised: ((will be filled in by the editorial staff)) Published online: ((will be filled in by the editorial staff))

\section{References}

[1] U.S Department of Energy, Annual Energy Outlook, Washington D.C., 2019.

[2] S. Hu, M. R. Shaner, J. A. Beardslee, M. Lichterman, B. S. Brunschwig, N. S. Lewis, Science 2014, 344, 1005.

[3] A. Kafizas, Y. Ma, E. Pastor, S. R. Pendlebury, C. Mesa, L. Francàs, F. Le Formal, N. Noor, M. Ling, C. Sotelo-Vazquez, C. J. Carmalt, I. P. Parkin, J. R. Durrant, ACS Catal. 2017, 7, 4896.

[4] K. Sun, F. H. Saadi, M. F. Lichterman, W. G. Hale, H.-P. Wang, X. Zhou, N. T. Plymale, S. T. Omelchenko, J.-H. He, K. M. Papadantonakis, B. S. Brunschwig, N. S. Lewis, Proc. Natl. Acad. Sci. USA 2015, 112, 3612.

[5] P. Roy, C. Das, K. Lee, R. Hahn, T. Ruff, M. Moll, P. Schmuki, J. Am. Chem. Soc. 2011, 133, 5629 .

[6] X. G. Zhang, Electrochemistry of Silicon and Its Oxide, Kluwer Academic, 2001.

[7] C. C. L. McCrory, S. Jung, I. M. Ferrer, S. M. Chatman, J. C. Peters, T. F. Jaramillo, J. Am. Chem. Soc. 2015, 137, 4347.

[8] K. Jun, Y. S. Lee, T. Buonassisi, J. M. Jacobson, Angew. Chemie Int. Ed. 2012, 51, 423.

[9] Z. Luo, B. Liu, H. Li, X. Chang, W. Zhu, T. Wang, J. Gong, Small Methods 2019, 0, 1900212.

[10] A. G. Scheuermann, J. P. Lawrence, K. W. Kemp, T. Ito, A. Walsh, C. E. D. Chidsey, P. K. Hurley, P. C. McIntyre, Nat. Mater. 2016, 15, 99.

[11] I. A. Digdaya, B. J. Trześniewski, G. W. P. Adhyaksa, E. C. Garnett, W. A. Smith, J. Phys. Chem. C 2018, 122, 5462.

[12] X. Zhou, R. Liu, K. Sun, K. M. Papadantonakis, B. S. Brunschwig, N. S. Lewis, Energy Environ. Sci. 2016, 9, 892.

[13] K. Oh, C. Mériadec, B. Lassalle-Kaiser, V. Dorcet, B. Fabre, S. Ababou-Girard, L. Joanny, F. Gouttefangeas, G. Loget, Energy Environ. Sci. 2018, 11, 2590.

[14] K. Oh, L. Joanny, F. Gouttefangeas, B. Fabre, V. Dorcet, B. Lassalle-Kaiser, A. Vacher, C. Mériadec, S. Ababou-Girard, G. Loget, ACS Appl. Energy Mater. 2019, 2, 1006.

[15] S. A. Lee, T. H. Lee, C. Kim, M. G. Lee, M.-J. Choi, H. Park, S. Choi, J. Oh, H. W. Jang, ACS Catal. 2018, 8, 7261.

[16] C.-W. Tung, T.-R. Kuo, C.-S. Hsu, Y. Chuang, H.-C. Chen, C.-K. Chang, C.-Y. Chien, Y.-J. Lu, T.-S. Chan, J.-F. Lee, J.-Y. Li, H. M. Chen, Adv. Energy Mater. 2019, 9 , 1901308.

[17] J. C. Hill, A. T. Landers, J. A. Switzer, Nat. Mater. 2015, 14, 1150.

[18] G. Xu, Z. Xu, Z. Shi, L. Pei, S. Yan, Z. Gu, Z. Zou, ChemSusChem 2017, 10, 2897. 


\section{WILEY-VCH}

[19] J. Chen, G. Xu, C. Wang, K. Zhu, H. Wang, S. Yan, Z. Yu, Z. Zou, ChemCatChem 2018, 10, 5025.

[20] M. G. Kast, L. J. Enman, N. J. Gurnon, A. Nadarajah, S. W. Boettcher, ACS Appl. Mater. Interfaces 2014, 6, 22830.

[21] Q. Ding, J. Zhai, M. Cabán-acevedo, M. J. Shearer, L. Li, H. Chang, M. Tsai, D. Ma, X. Zhang, R. J. Hamers, J.-H. He, S. Jin, Adv. Mater. 2015, 27, 6511.

[22] H.-P. Wang, K. Sun, S. Y. Noh, A. Kargar, M.-L. Tsai, M.-Y. Huang, D. Wang, J.-H. He, Nano Lett. 2015, 15, 2817.

[23] I. Oh, J. Kye, S. Hwang, Nano Lett. 2012, 12, 298.

[24] G. Bhargava, I. Gouzman, C. M. Chun, T. A. Ramanarayanan, S. L. Bernasek, Appl. Surf. Sci. 2007, 253, 4322.

[25] G. Loget, B. Fabre, S. Fryars, C. Mériadec, S. Ababou-Girard, ACS Energy Lett. 2017, 2, 569 .

[26] M. J. Kenney, M. Gong, Y. Li, J. Z. Wu, J. Feng, M. Lanza, H. Dai, Science 2013, 342, 836.

[27] C. D. Wagner, J. F. Moulder, L. E. R. Davis, W. M. Riggs, Hand Book of X-Ray Photoelectron Spectroscopy, 2008. 


\section{WILEY-VCH}

Silicon is a promising photoelectrode substrate, however, its low stability prevents its use as a photoanode for oxygen evolution reaction (OER). Here, we show that Fe nanoparticles, electrodeposited onto $n$-Si can promote hole transfer for OER. The influence of the Si surface coverage, the Si structure as well as the electrolyte $\mathrm{pH}$ is studied in details.

Photoelectrochemical water splitting

Kiseok Oh, Vincent Dorcet, Bruno Fabre and Gabriel Loget*

Dissociating water at $n$-Si photoanodes partially covered with Fe catalysts

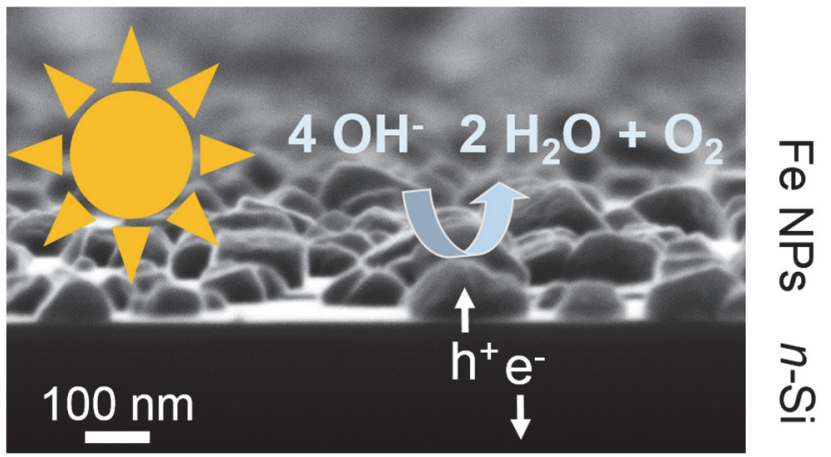




\section{WILEY-VCH}

Copyright WILEY-VCH Verlag GmbH \& Co. KGaA, 69469 Weinheim, Germany, 2018.

\section{Supporting Information}

\section{Dissociating water at n-Si photoanodes partially covered with Fe catalysts}

Kiseok Oh, Vincent Dorcet, Bruno Fabre and Gabriel Loget*

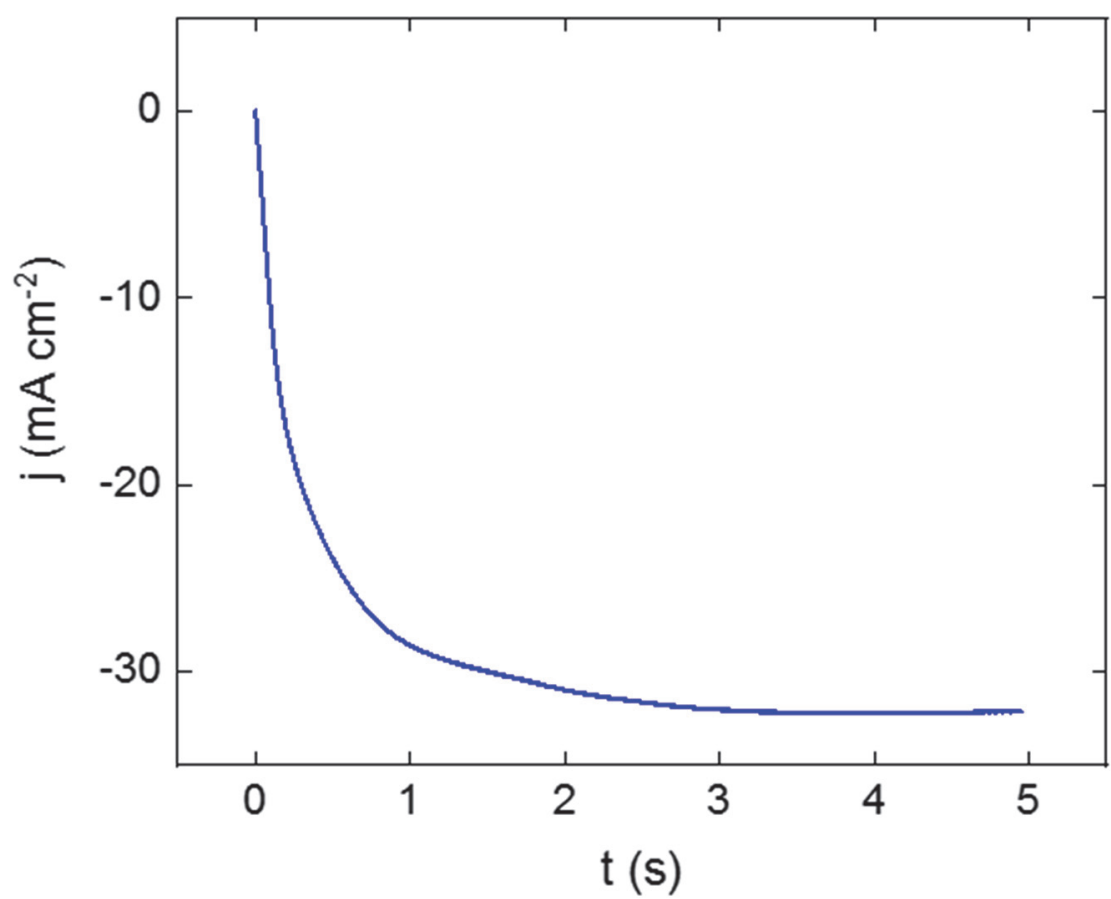

Figure S1. Typical chronoamperogram obtained for the electrodeposition of $\mathrm{Fe}$ on freshly-hydrogenated $n$-Siplanar at $-1.5 \mathrm{~V}$ vs SCE. 


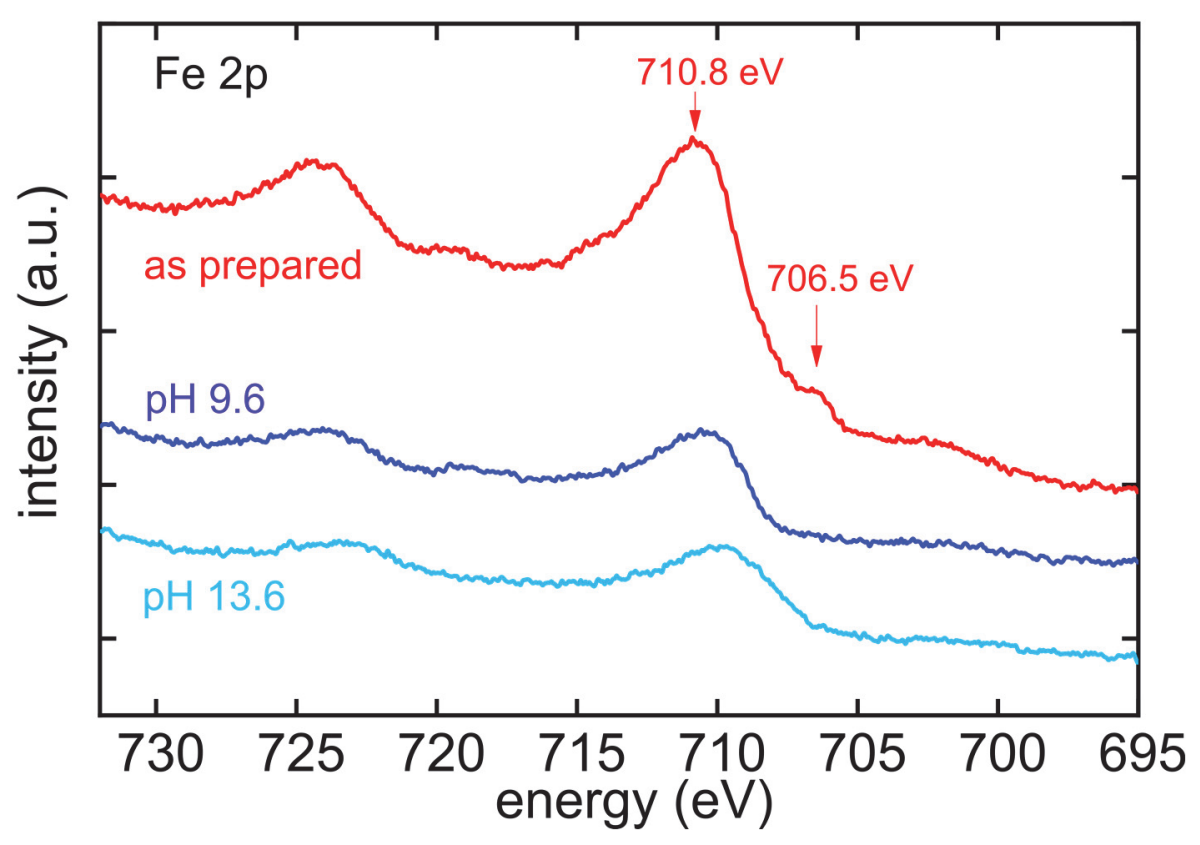

Figure S2. XPS spectra showing the Fe $2 p$ region for $n$-Siplanar $(2 s)$ (red) as prepared, (dark blue) after $1 \mathrm{~h}$ electrolysis in Li/K borate at $2.3 \mathrm{~V}$ vs RHE and (clear blue) after 1 h electrolysis in $1 \mathrm{M} \mathrm{NaOH}$ borate at $2 \mathrm{~V}$ vs $\mathrm{RHE}$. The peak $2 \mathrm{p}_{3 / 2}$ position corresponding to $\mathrm{Fe}^{0}(706.5 \mathrm{eV})$ and oxidized $\mathrm{Fe}(710.8 \mathrm{eV})$ are shown by arrows. The peak around 724 eV corresponds to Fe 3p1/2. 


\section{WILEY-VCH}
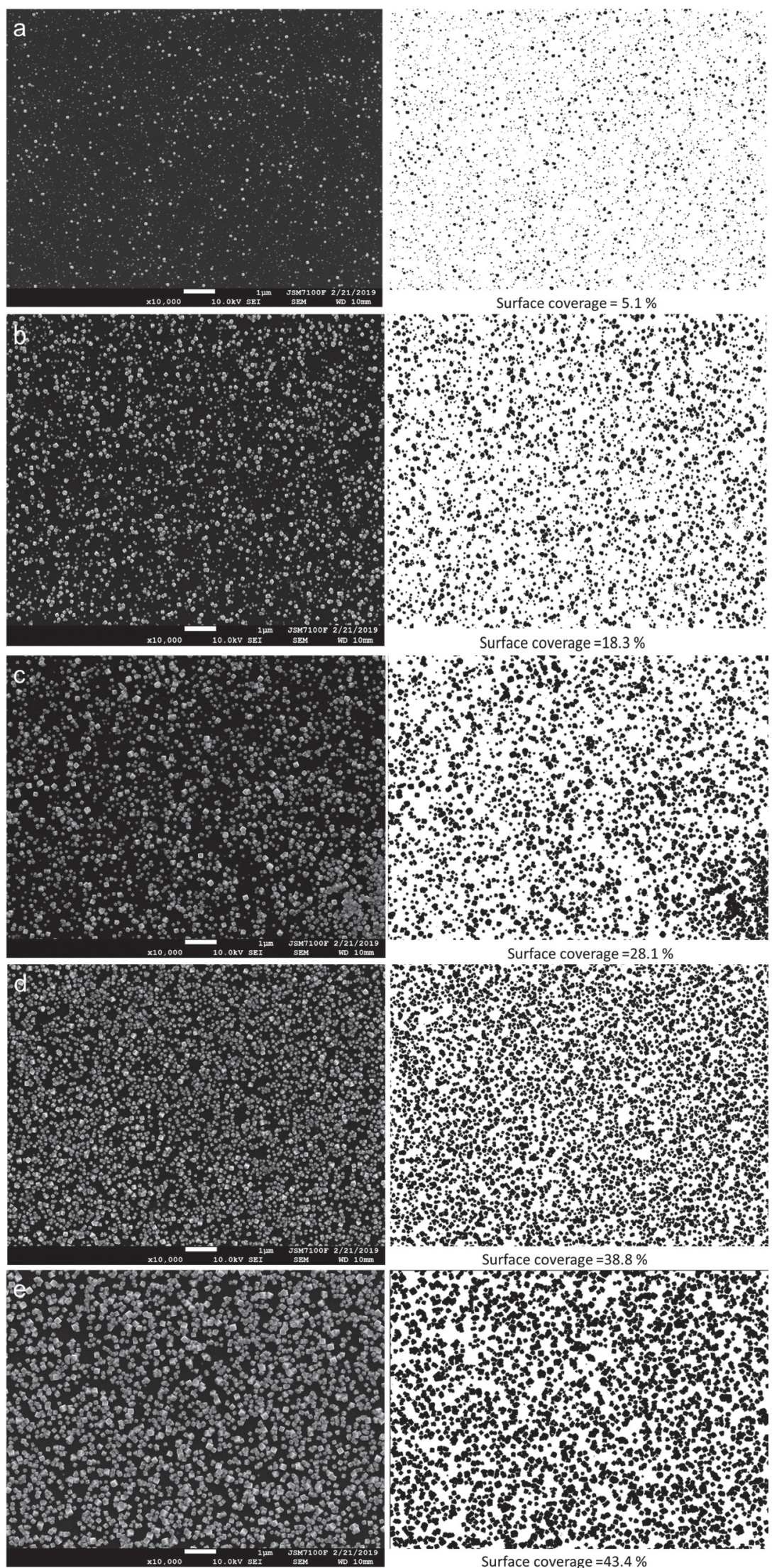

Figure S3. SEM images of $n$-Siplanar with different electrodeposition times. Electrodeposition time varied from $0.5 \mathrm{~s}$ to $5 \mathrm{~s}$. a) $0.5 \mathrm{~s}$, b) $1 \mathrm{~s}, \mathrm{c}) 2 \mathrm{~s}$, d) $3 \mathrm{~s}$ and e) $5 \mathrm{~s}$ respectively. All the images were converted into binary images then surface coverage was calculated using the freeware imageJ. 


\section{WILEY-VCH}

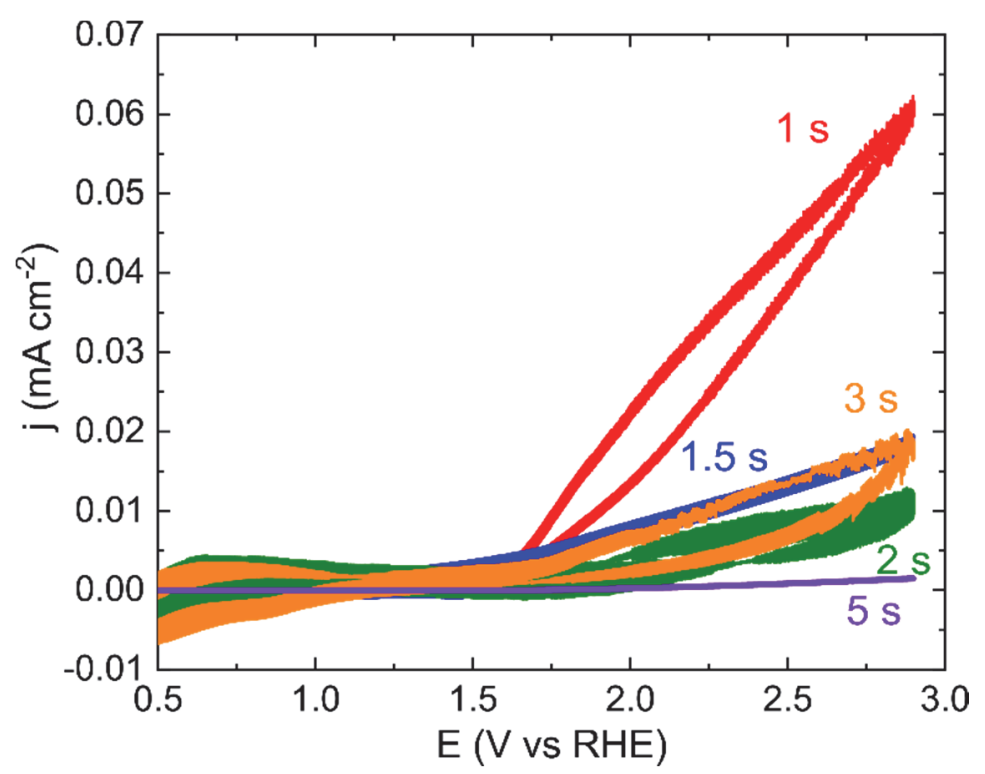

Figure S4. CVs recorded at $100 \mathrm{mV} \mathrm{s}^{-1}$ in the dark on various $n$-Siplanar/Fe(tedep) surfaces in $1 \mathrm{M} \mathrm{NaOH}$ (tedep is indicated for each CV). 
WILEY-VCH

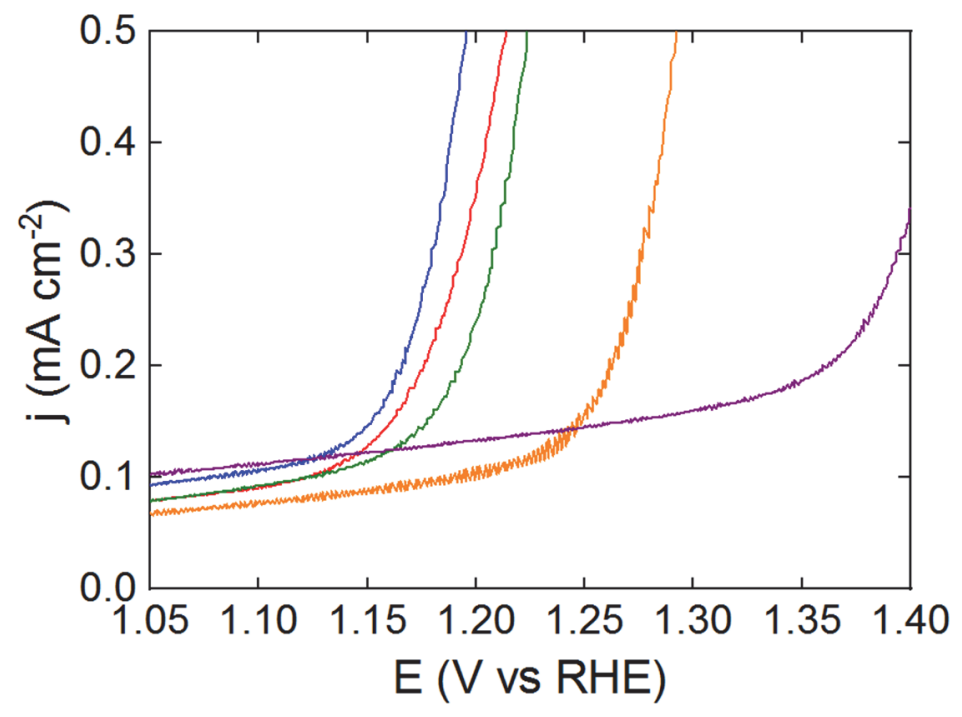

Figure S5. Linear sweep voltammograms (scan rate $=100 \mathrm{mV} \mathrm{s}^{-1}$ ) recorded under illumination in $1 \mathrm{M} \mathrm{NaOH}$ on $n$-Siplanar/Fe(1s) (red), $n$-Siplanar/Fe(1.5s) (blue), $n$ Siplanar $/ F e(2 s)$ (green), $n$-Siplanar/Fe(3s) (orange), and $n$-Siplanar/Fe(5s) (purple). 


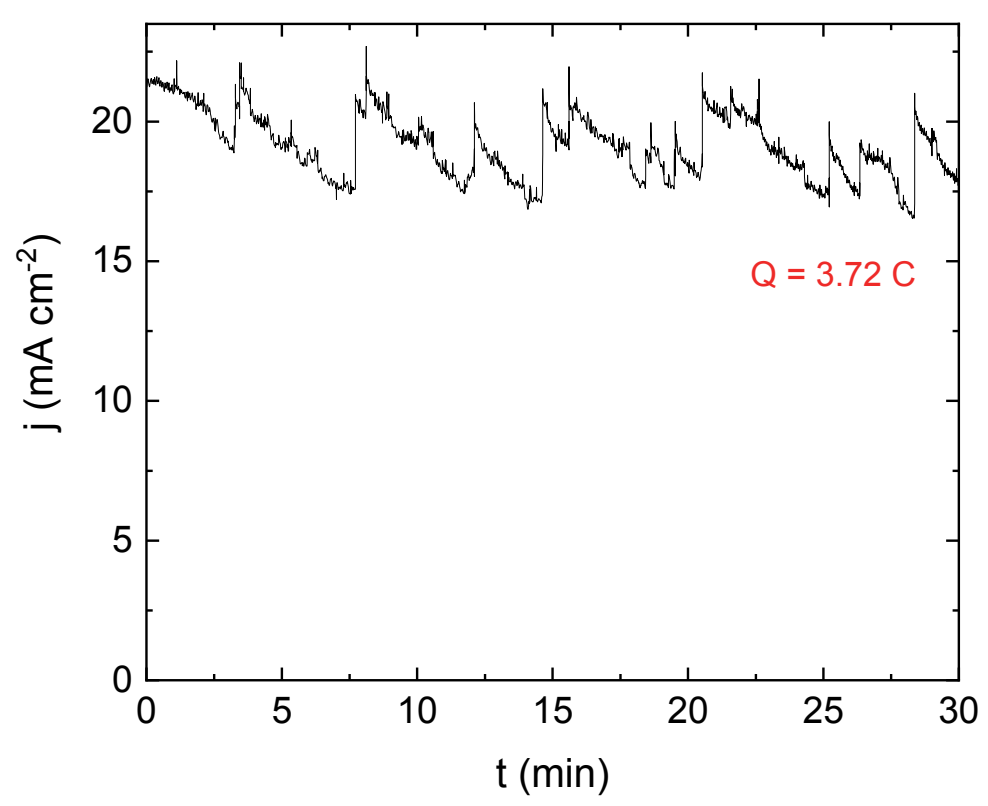

Figure S6. Chronoamperogram recorded during the preparative-scale electrolysis on $n$-Siplanar $/ \mathrm{Fe}(2 \mathrm{~s})$ in $\mathrm{Li} / \mathrm{K}$ borate at $2.3 \mathrm{~V}$ vs $\mathrm{RHE}$, the geometrical surface area of the photoanode was $0.108 \mathrm{~cm}^{2}$. 


\section{WILEY-VCH}

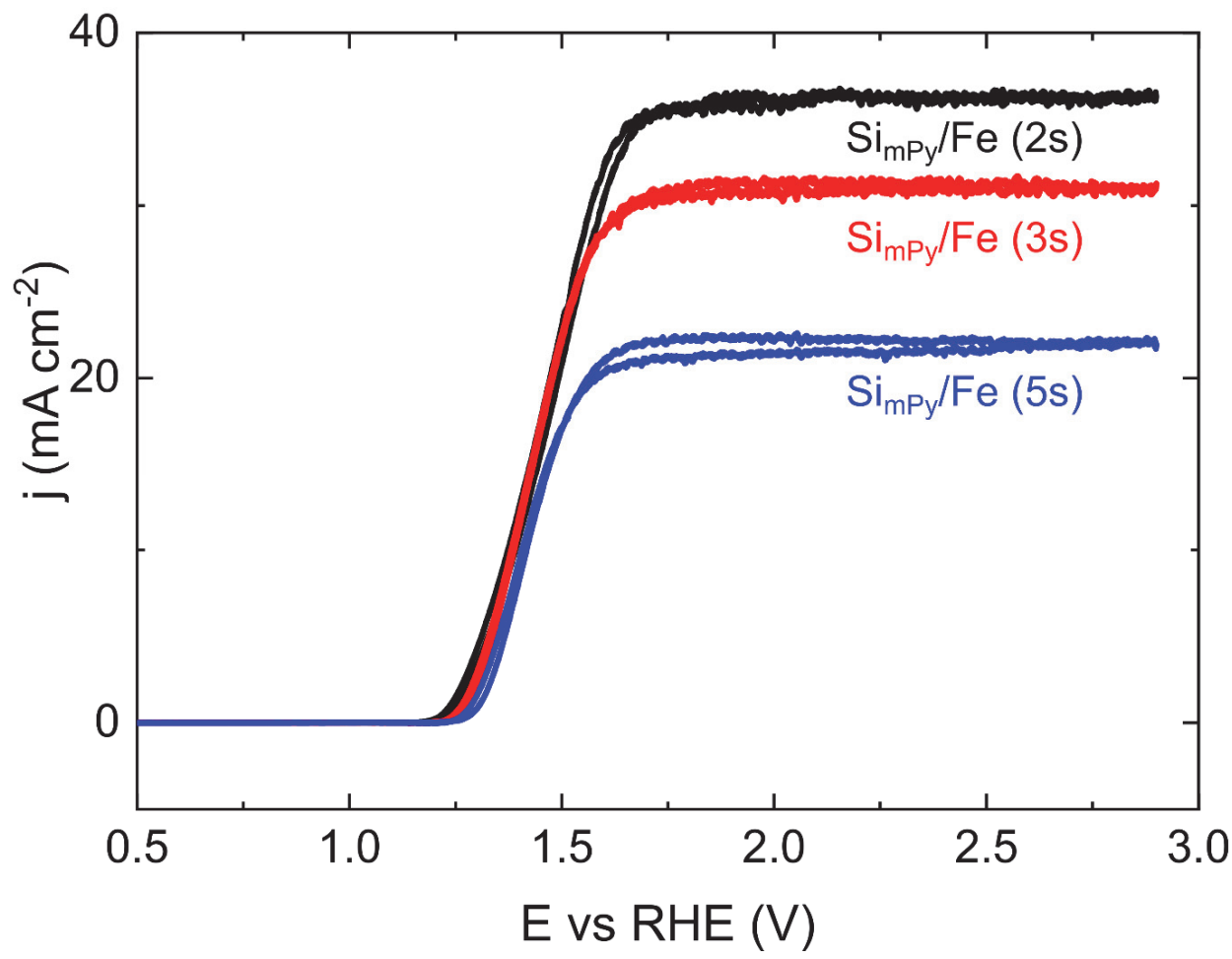

Figure S7. CVs recorded at $100 \mathrm{mV} \mathrm{s}^{-1}$ under illumination on $n-\mathrm{SimPy}_{\mathrm{mPe}} / \mathrm{Fe}$ in $1 \mathrm{M} \mathrm{NaOH}$. 


\section{WILEY-VCH}

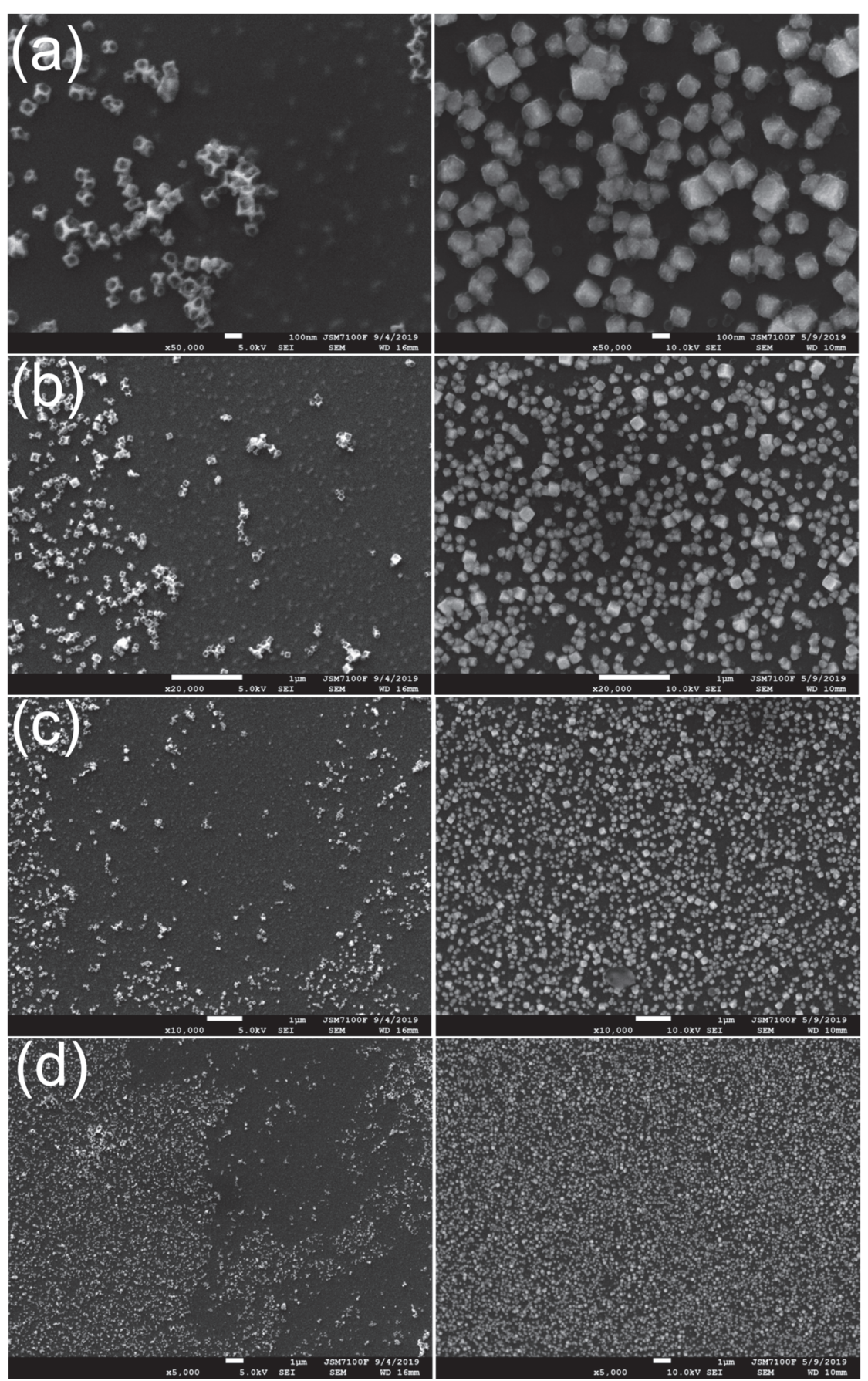

Figure S8. SEM images recorded on $n$-Siplanar/Fe(2s) (left column) after $3 \mathrm{~h}$ of CA at 2 $\mathrm{V}$ vs RHE in $\mathrm{NaOH}$ and (right column) after $130 \mathrm{~h}$ of $\mathrm{CA}$ at $2.3 \mathrm{~V}$ vs RHE in Li/K borate at several magnifications: a) 50 000x times, b) 20 000x, c) 10 000x and d) 5 000x. 
Table S1. Values of maximum photocurrent density $\left(j_{\max }\right)$, onset potential ( $\left.E_{\text {onset }}\right)$, stability in operation $\left(t_{\text {stab }}\right)$ for $n$-Si-based photoanodes prepared by electrodeposition, the values obtained for $n$-Si-based and $n^{+}-n$-Si-based coated by ALD with $\mathrm{Fe}_{2} \mathrm{O}_{3}$ is also indicated for comparison.

\begin{tabular}{|c|c|c|c|c|c|c|}
\hline & Electrode & pH & $\begin{array}{c}j_{\max } \\
\left(\mathbf{m A ~} \mathbf{c m}^{-2}\right)\end{array}$ & $\begin{array}{c}E_{\text {onset }} \\
(V \text { vs RHE })^{\mathrm{e}}\end{array}$ & $t_{\text {stab }}(\mathbf{h})^{\mathrm{f}}$ & ref \\
\hline \multirow{12}{*}{$\operatorname{Edep}^{\mathbf{a}}$} & $n-\mathrm{Si}_{\text {planar }} / \mathrm{Co}$ & 14 & 34 & $\sim 1.1$ & 2 & 17 \\
\hline & $n-\mathrm{Si}_{\text {planar }} / \mathrm{Co}$ & 9 & $>20$ & $\sim 1.2$ & $\begin{array}{c}120 \\
@ j=8 \mathrm{~mA} \mathrm{~cm}^{-2}\end{array}$ & 17 \\
\hline & $n-\mathrm{Si}_{\text {planar }} / \mathrm{Ni}$ & 14 & 33 & 1.11 & 10 & 24 \\
\hline & $n-\mathrm{Si}_{\text {planar }} / \mathrm{Ni}$ & 13.6 & 36 & 1.03 & n.c. & 18 \\
\hline & $n-\mathrm{Si}_{\text {planar }} / \mathrm{Ni}$ & 9 & n.c. & n.c. & $\begin{array}{c}300 \\
\varrho_{j} j=8 \mathrm{~mA} \mathrm{~cm}^{-2}\end{array}$ & 18 \\
\hline & $n-\mathrm{Si}_{\text {planar }} / \mathrm{Ni}$ & 14 & 32 & 1.08 & 7 & 15 \\
\hline & $n$-Si planar $/ \mathrm{Ni} / \mathrm{Co}$ & 14 & 37 & 1.02 & n.c. & 19 \\
\hline & $n-\mathrm{Si}_{\text {planar }} / \mathrm{Ni} / \mathrm{Co}$ & 9 & n.c. & n.c. & $\begin{array}{c}100 \\
\varrho_{j} j=6 \mathrm{~mA} \mathrm{~cm}^{-2}\end{array}$ & 19 \\
\hline & $n-\mathrm{BSi}^{\mathrm{b}} / \mathrm{Ni} / \mathrm{NiFe}$ & 13.6 & 22 & 1.12 & 8.5 & 14 \\
\hline & $n-\mathrm{Si}_{\text {planar }} \mathrm{c} / \mathrm{Fe}$ & 13.6 & 20 & 1.19 & 4 & this work \\
\hline & $n-\mathrm{Si}_{\text {planar }} / \mathrm{Fe}$ & 9.6 & 24 & 1.29 & 128 & this work \\
\hline & $n-\mathrm{Si}_{\mathrm{mPy}} / \mathrm{Fe}$ & 9.6 & 34 & 1.25 & $>11$ & this work \\
\hline \multirow{2}{*}{ ALD } & $n-\mathrm{Si}_{\text {planar }} / \mathrm{Fe}_{2} \mathrm{O}_{3}$ & 13.8 & 31 & $\sim 1.1$ & n.c. & 8 \\
\hline & $n^{+} n-\mathrm{Si}_{\mathrm{NW}} \mathrm{d} / \mathrm{Fe}_{2} \mathrm{O}_{3}$ & 13.8 & 42.5 & $\sim 1$ & n.c. & 8 \\
\hline
\end{tabular}

${ }^{\mathrm{a}} \mathrm{Edep}=$ electrodeposited, ${ }^{\mathrm{b}} \mathrm{BSi}=\mathrm{Black} \mathrm{Si},{ }^{\mathrm{c}}$ the results reported for this work were obtained for an electrodeposition time of $2 \mathrm{~s},{ }^{\mathrm{d}} \mathrm{Si}_{\mathrm{NW}}=\mathrm{Si}$ nanowires, ${ }^{\mathrm{e}}$ measured arbitrarily at $200 \mu \mathrm{A} \mathrm{cm}^{-2},{ }^{\mathrm{f}} t_{\mathrm{stab}}=$ stability in operation (unless specified, defined here as the time needed to reach $80 \%$ of $j_{\max }$ ) 